\title{
Food Security and the Role of Agricultural Research
}

\section{Timothy Reeves}

Director General, CIM MYT, M exico City, M exico

\section{Per Pinstrup-Andersen}

Director General, International Food Policy Research Institute, Washington, DC

\section{Rajul Pandya-Lorch}

Special Assistant, International Food Policy Research Institute, Washington, DC

Despite impressive growth in food production in recent decades, the world is not food secure. Even if available food energy were evenly distributed within each country - which it is not - 33 countries would not be able to assure sufficient food energy (2,200 calories per person per day) for their populations.

Over 800 million people in the developing world, or 20 percent of the population, are food insecure, more than 180 million preschool children are malnourished, and many hundreds of millions of people suffer from diseases of hunger and malnutrition.

With two-thirds of the developing world's undernourished, Asia remains the main area of concern whereas food security is rapidly deteriorating in SubSaharan Africa. The number of undernourished people in the latter region almost doubled in two decades from 94 million in 1969-71 to 175 million in $1988-90$, and the proportion of the population that is undernourished rose from 35 percent to 37 percent. Between 1988-90 and 2010, the number of undernourished people is projected to increase by 70 percent to 296 million, 32 percent of the region's population. By 2010, almost half of the developing world's undernourished will be located in Sub-Saharan Africa, up from 10 percent in 1969-71.

Hunger is a consequence of poverty. An estimated 1.3 billion people live in households that earn a dollar a day or less per person. Fifty percent of these absolutely poor people live in South Asia, 19 percent in Sub-Saharan Africa, 15 percent in East Asia, and 10 percent in Latin America and the Caribbean. Almost one-half of the population of South Asia and Sub-Saharan Africa and one-third of that in the Middle East and N orth Africa live in poverty. 
Poverty in the developing world is not expected to diminish much in the near future. The total number of poor people is projected to remain around 1.3 billion in 2000 , although regional shifts in the distribution of total poverty are anticipated. Sub-Saharan Africa will increasingly become a new locus of poverty: the number of poor is expected to increase by 40 percent between 1990 and 2000, and the region's share of the developing world's poor is expected to increase from 19 percent to 27 percent over this period. South Asia will continue to be home to half the world's poor; the number of poor in that region is expected to decline by only 10 percent between 1990 and 2000.

Growth in food production in recent decades has been impressive. During the period 1961-93, cereal production worldwide more than doubled from 877 million tons to 1,894 million tons; in developing countries it almost tripled from 396 million tons to 1,089 million tons. Since 1950, grain production per person has increased about 100 kilograms per person worldwide and about 80 kilograms per person in developing countries as a group.

Of note on the food production front is the role of yield increases, which have been the source of 92 percent of the increased cereal production in the developing world between 1961 and 1990; expansion of area planted in cereal crops contributed eight percent. While cultivated area is still increasing in most developing countries, it is doing so at a low and declining rate. Yield trends in developing countries climbed steadily upward for the three major cereals rice, maize, and wheat - between the 1960s and late 1980s. Yield increases were notably high in Asia: during 1961-91 rice yields doubled from 1.7 tons to 3.6 tons per hectare, wheat yields increased from 0.7 tons to 2.5 tons per hectare, and maize yields almost tripled from 1.2 tons to 3.4 tons per hectare.

Yield growth rates in some areas are stagnating and, in a few cases, falling. A slowdown in the rate of increase of yields of major cereals raises concern because increased yields will have to be the source of increased food production in the future. Most cultivable land in Asia, North Africa, and Central America has al ready been brought under cultivation, and physical and technological constraints, as well as environmental considerations, are likely to restrain largescale conversion of potentially cultivable land in Sub-Saharan Africa and South America. The option of area expansion as a source of food production increases is rapidly disappearing, and even Africa will have to rely mostly on increased yields to expand food production.

Another cause of concern on the food production front is the leveling off during the 1980s and early 1990s of grain production per person for the world and for the developing countries as a group, after steady increases during the 1950s, 1960s, and 1970s. Since mid-1980, global grain production per person has decreased, and grain production for developing countries as a group has been constant. If corrective actions are not taken soon, this trend could turn downward, with potentially adverse repercussions, not just because the additional population needs adequate food but because factors in addition to 
population growth are pushing up demand for grain. While future demand for grain for direct consumption in developing countries is expected to grow at a rate only slightly above population growth, the expected growth rate in world demand for feed grain is more than twice the expected population growth rate. Once incomes increase beyond a certain level, demand for feed grain increases rapidly; most developing countries have incomes still below the level at which feed grain use increases rapidly.

\section{The Role of Agricultural Research}

Existing technology and knowledge will not permit the necessary expansions in food production to meet needs. Low-income developing countries are grossly underinvesting in agricultural research compared with industrialized countries, even though agriculture accounts for a much larger share of their employment and incomes. Their public sector expenditures on agricultural research are typically less than 0.5 percent of agricultural gross domestic product, compared with about two percent in higher-income developing countries and two percent to five percent in industrialized countries.

Investment in agricultural research must be accelerated if developing countries are to assure future food security for their citizens at reasonable prices and without irreversible degradation of the natural resource base. Accelerated investment in agricultural research is particularly important and urgent for lowincome developing countries, partly because these countries will not achieve reasonable economic growth, poverty alleviation, and improvements in food security without productivity increases in agriculture, and partly because so little research is currently undertaken in these countries. The negative correlation between investment in agricultural research and a country's income level is very strong. Poor countries, which depend the most on productivity increases in agriculture, grossly underinvest in agricultural research.

Agricultural research has successfully developed yield-enhancing technology for the majority of crops grown in temperate zones and for several crops grown in the tropics. The dramatic impact of agricultural research and modern technology on wheat and rice yields in Asia and Latin America since the mid1960s is well known. Less dramatic but significant yield gains have been obtained from research and technological change in other crops, particularly maize.

Large yield gains currently being obtained in many crops at the experimental level offer great promise for future yield and production increases at the farm level. In addition to raising yield levels, research resulting in tolerance or resistance to adverse production factors such as pests and drought, leading to biological and integrated pest control, and to develop improved varieties and hybrids for agroecological zones with less than optimal production conditions reduces risks and uncertainty and enhances sustainability in production through better management of natural resources and reduced environmental risks. 
Accelerated agricultural research aimed at more-favored areas will reduce pressures on fragile lands in less-favored areas. Future research for the former must pay much more attention to sustainability than in the past to avoid a continuation of extensive waterlogging, salination, and other forms of land degradation. But, a continuation of past low-priority on less-favored agroecological zones is inappropriate and insufficient to achieve the goals of poverty alleviation, improved food security, and appropriate management of natural resources. More research resources must be dedicated to less-favored areas, those with agricultural potential, fragile lands, poor rainfall, and high risks of environmental degradation. A large share of the poor and food insecure reside in these agroecological zones.

The low priority given to research to develop appropriate technology for lessfavored agroecological zones in the past is a major reason for the current rapid degradation of natural resources and high levels of population growth, poverty, and food insecurity. Much more research must be directed at developing appropriate technology for these areas. Out migration is not a feasible solution for these areas in the foreseeable future simply because of the large numbers of poor people who reside there and the lack of alternative opportunities elsewhere. Strengthening agriculture and related nonagricultural rural enterprises is urgent and must receive high priority.

Following on the tremendous successes popularly referred to as the Green Revolution, the international agricultural research centers under the auspices of the CGIAR have recognized the importance and urgency of research to assure sustainability in agricultural intensification through appropriate management of natural resources. Thus management of natural resources and conservation and enhancement of germplasm are given high priority in current and future research by the centers.

Declining investment in agricultural research for developing countries since the mid-1980s by both developing-country governments and international foreign assistance agencies is inappropriate and must be reversed. While privatization of agricultural research should be encouraged, much of the agricultural research needed to achieve food security, reduce poverty, and avoid environmental degradation in developing countries is of a public goods nature and will not be undertaken by the private sector. Fortunately, while private rates of return may be insufficient to justify private-sector investment, expected high social rates of returns justify public investment. The major share of such investment should occur in the developing countries' own research institutions (NARS); there is an urgent need to strengthen these institutions to expand research and increase the probability of high payoffs.

The centers under the auspices of the CGIAR have a well-defined role to play in support of the work by NARS, namely to undertake research of a public goods nature with large international externalities and to strengthen the research capacity of the NARS and networking among NARS, international 
centers, and research institutions in the industrialized nations. Research institutions in the industrialized nations have played an extremely important role by undertaking basic research required to support strategic, adaptive, and applied research by the international centers and the NARS and by providing training for developing-country researchers. Collaboration among developedcountry research institutions, CGIAR centers, and NARS in developing countries is widespread, but further strengthening is required to make full use of the comparative advantages of each of the three groups for the ultimate benefit of the poor in developing countries.

All appropriate aspects of science, including molecular biology-based research, must be mobilized to solve poor people's problems. Almost all of the investment made in genetic engineering and biotechnology for agriculture during the last 10 to 15 years has been focused on solving problems in temperate-zone agriculture such as herbicide resistance in cotton, longer shelf life for perishable products such as tomatoes, and a variety of other problems of importance in the industrialized nations. If we are serious about hel ping poor people, particularly poor women, and if we are serious about assuring sustainability in the use of natural resources, we must use all appropriate tools at our disposal to achieve these goals, including modern science. For example, modern science may help eliminate losses resulting from drought among small farmers in West Africa. Drought-tolerant varieties of maize that poor African farmers can grow could potentially be developed, along with crop varieties with tolerance or resistance to other adverse conditions, including certain insects and pests.

While some argue that it is too risky to use genetic engineering to solve poor people's problems because we may be unaware of future side effects, we believe that it is unethical to withhold solutions to problems that cause thousands of children to die from hunger and malnutrition. Clearly, we must seek acceptable levels of biosafety before releasing products from modern science, but it is critical that the risks associated with the solutions be weighed against the ethics of not making every effort to solve food and nutrition problems.

Effective partnerships between developing-country research systems, international research institutions, and private and public sector research institutions in industrialized countries should be forged to bring biotechnology to bear on the agricultural problems of developing countries. Incentives should be provided to the private sector to undertake biotechnology research focused on the problems of developing-country farmers. Failure to expand agricultural research significantly in and for developing countries will make food security, poverty, and environmental goals elusive. Lack of foresight today will carry a very high cost for the future. As usual, the weak and powerless will carry the major burden, but just as we must all share the blame for inaction or inappropriate action so will we all suffer the consequences. 


\section{References}

International Food Policy Research Institute (IFPRI). 1995. A 2020 Vision for Food, Agriculture, and the Environment: The Vision, Challenge, and Recommended Action. Washington, D.C.: IFPRI

Pardey, P., J. Roseboom, and N. Beintema. 1994. Agricultural research in Africa: Three Decades of Devel opment. Briefing Paper N o. 19. The Hague, N etherlands: International Service for National Agricultural Research

Pinstrup-Andersen, Per, and Rajul Pandya-Lorch. 1995. Poverty, Food Security, and the Environment: 2020. Brief N 0. 29. Washington, D.C.: International Food Policy Research Institute . 1994. Alleviating Poverty, Intensifying Agriculture, and Effectively Managing $N$ atural Resources. Food, Agriculture, and the Environment Discussion Paper N o. 1. Washington, D.C.: International Food Policy Research Institute

Rosegrant, Mark W., Mercedita Agcaoili-Sombilla, and Nicostrato Perez. 1995. "Global food supply, demand, trade to 2020: Projections and implications for policy and investment." IFPRI, Washington, D.C. Mimeo

Scherr, Sara, and Satya Yadav. 1996. Land Degradation in the Developing World: Implications for Food, Agriculture, and the Anvironment to 2020. Food Agriculture, and the Environment Discussion Paper No. 14. Washington, D.C.: International Food Policy Research Institute. 